\title{
Revitalizing Astronomy in the Philippines
}

\author{
Cynthia P. Celebre and Bernardo M. Soriano Jr \\ PAGASA (Weather Bureau), 1424 ATB, Quezon Ave, 1104 Quezon \\ City, Philippines.e-mail: cynthia_celebre@hotmail.com and \\ bolonging_soriano@yahoo.com
}

\begin{abstract}
Aware of the possibility that astronomy in the Philippines will remain as lethargic as it has been for a hundred years if drastic changes are not made, various revitalizing activities were planned in 1997 and some have been implemented. These activities were divided into five categories and included the promotion of astronomy throughout the country and the attendance of some personnel of the Atmospheric, Geophysi$\mathrm{cal}$ and Space-Sciences Branch at various international meetings. Project proposals were also prepared and submitted to various local and foreign institutions in order to acquire astronomical equipment. The Philippines also applied for, and received, associate mebership of the International Astronomical Union.
\end{abstract}

\section{Historical Background}

Work in astronomy in the Philippines started in 1897. It was one of the functions of the "Observatorio de Meteorologico de Manila" (OMM), which performed not only meteorological and astronomical services but also seismological and terrestrial magnetism services. Its astronomical activities were mostly limited to timekeeping and observation of solar and stellar phenomena.

The OMM began as a private institution in 1865 and became a government agency as the Weather Bureau in 1901 with its observatory in Manila as its central office. During the Second World War, the astronomical observatory was destroyed and a new observatory was constructed within the campus of the University of the Philippines in Quezon City in 1954. It remained there up to the present time, now under the Philippine Atmospheric, Geophysical and Astronomical Services Administration (PAGASA), as the only government observatory. From 1954, the observatory has not seen any major change up to the present time (1999). The construction of a planetarium in the PAGASA Science Garden in Quezon City in September 1977 is the only addition to the facilities of the agency.

Likewise, its activities are practically the same, except for the publication of astronomical data and the conduct of occasional telescope and stargazing sessions up to 1993 . The revitalizing activities in astronomy in the Philippines 
began in 1997 with the celebration of the centennial of astronomy in the country. This paper will describe these activities.

\section{Resources and Activities in Astronomy}

At present, only PAGASA, the National Museum (NM) Planetarium, and the Manila Observatory (MO) undertake activities in astronomy in the Philippines. The NM Planetarium is under the Department of Education, Culture and Sports and is located at the Rizal Park in Luneta, Manila. The MO is a private institution in Quezon City that also conducts geophysical and astronomical observations and researches, some in cooperation with PAGASA. The succeeding paragraphs describe the resources and activities of PAGASA in astronomy. A section deals with the programs of the agency to revitalize astronomy in the Philippines.

\subsection{Resources}

PAGASA, now under the Department of Science and Technology (DOST), is composed of nine branches or divisions. Each branch/division is composed of sections. A section in astronomy is under the Atmospheric, Geophysical and Space Sciences Branch (AGSSB), which is basically the research and training arm of PAGASA. The Astronomy Research and Development Section (AsRDS) of AGSSB is staffed by 17 professional-level employees who hold college degrees, and by 17 sub-professional-level employees.

Since 1969, PAGASA has established a solar-radiation observation network that consists of 52 stations as of 1999 . Ten of the stations are operated by the National Solar-Radiation Center (NSRC) under the AsRDS, AGSSB while the other divisions of PAGASA run the rest.

The NSRC maintains the instruments of, and produces the sunshine cards, for the network. The network records sunshine duration, and global, diffuse, direct, infrared and ultraviolet radiation. The solar-radiation data are sent to international solar-radiation centers for collation with other worldwide observations and for publication. The processed data are returned to the NSRC for its database.

As earlier mentioned, PAGASA has an astronomical observatory and a planetarium, which are both managed by the AsRDS, AGSSB. The observatory has twelve telescopes of various sizes, the largest five of which are the $30-\mathrm{cm}$ reflector and four 25-cm reflectors. The other telescopes are of the refractor type; two each of apertures $15 \mathrm{~cm}$ and $10 \mathrm{~cm}$, while the rest are of $7.5-\mathrm{cm}$ aperture. One of the $15-\mathrm{cm}$ telescopes is permanently installed at the Observatory. There are six other telescopes, which are also of the refractor type and have an aperture of 7.5 $\mathrm{cm}$, that are distributed among the field meteorological stations of PAGASA. In addition, private individuals and institutions own 38 telescopes. The biggest of these is the $58-\mathrm{cm}$ reflecting Newtonian telescope at the Science Centrum in Manila.

Procured in June 1998, only the first 25-cm Cassegrain telescope of PAGASA is equipped with a CCD camera, which is still not functional because a suitable air-conditioning system is not yet in place. A photographic camera was acquired in 1997 to record special astronomical observations like eclipses and 
the appearance of comets and meteors. A small video camera was procured in October 1998 for similar purposes.

In addition to telescopes, the astronomical observatory is equipped with a quartz clock for determining the time up to the nearest tenth of a second. The clock is at least twelve years old and needs to be replaced by modern timekeeping equipment. The transceiver that was used for transmission of time to the field meteorological stations has been inoperative for almost seven years and has not been replaced due to budgetary constraints. A global positioning system (GPS) was acquired in 1998 for time comparison with the quartz clock.

The Planetarium at the Science Garden can seat 88 people. AsRDS personnel give astronomical shows to visitors, who are mostly students and teachers in elementary and high schools. The visitors are charged a minimal entrance fee to help defray part of the maintenance expenses.

\subsection{Activities of the astronomy section}

The principal activities of the astronomy section of PAGASA (AsRDS) consist of sunspot and lunar-occultation observations and solar- radiation measurements. It also makes observations of the satellites of Jupiter and the transits of Mercury, of comets and of other planets. From 1980 to 1984, the Observatory made observations of variable stars. It observes astronomical phenomena that are seen in the country such as the three total solar eclipses in the century, whose paths of totality crossed the Philippines. The astronomy section receives and subscribes to international publications and, in turn, publishes data that are derived from computations based on the publications. Among its important and widely used publications are the Almanac for Geodetic Engineers, rising and setting tables for the Sun and Moon, for the Philippines and for selected fishing areas, a daylight-duration table, and calendar (Julian) data, and lunar data which are intended for the observance of the Ramadan by Filipino Muslims. The publications are one of the principal sources of income of the AsRDS.

The other important activity of the AsRDS is time-keeping. The agency was designated by law to be the official time-keeper of the Philippines. It used to perform this function through a radio transceiver. However, its radio equipment has become inoperative so that even the meteorological stations in the field have not been receiving time signals for nearly five years now. The only means of disseminating time at present is the telephone.

Lastly, PAGASA engages in the promotion of astronomy, including space science in the Philippines, through its planetarium shows and the publication of astronomical posters. Its staff conducts and/or serves as resource speakers in lectures and seminars on astronomy and stargazing and telescoping sessions in various parts of the country. It coordinates and collaborates with other agencies or institutions in this field, such as the organization of astronomical societies in the colleges or universities.

Currently, there are ten astronomical societies with a total membership of about 300 students. It should be stressed, however, that there is only one educational institution that offers a course related to astronomy or space science in the country. No college or university gives a full course in astronomy in the Philippines. 
Personnel who do not have any formal education in astronomy perform all of the preceding activities. The knowledge of astronomy that they possess is obtained through the in-service training courses conducted by the agency and through the books that were procured, usually from overseas sources.

The training courses in astronomy in the Philippines are very infrequent mainly due to the lack of resource persons or lecturers in this field. Only two courses during the last 15 years have been held. The first of these was conducted by the Manila Observatory for the professional-level "astronomers" of the PAGASA in 1981 while the last one was held by the agency for astronomical observers in 1993 . The rarity of training courses can likewise be attributed to the lack of opportunities in astronomy in the Philippines, as there are very limited staff positions in the AsRDS, the sole unit that deals in astronomy in the PAGASA.

\subsection{Revitalizing activities}

Promotion of astronomy: Celebration of National Astronomy Week. On 24 February 1993, Presidential Proclamation No. 130 declaring the third week of February of every year as the National Astronomy Week (NAW) was issued through the initiative of PAGASA and the Philippine Astronomical Society (PAS), Inc. It stressed the universal appeal of astronomy as it encompasses all fields of human interest and endeavor. It emphasized that the study of astronomy, especially by the youth, will afford a better understanding of our planet, and thereby encourage them to participate more actively in the conservation and preservation of the environment. Moreover, it underscored the need to focus the people's attention on the significant contributions of astronomy in the advancement of the other sciences such as mathematics, physics, chemistry, biology, etc.

To celebrate the first NAW, PAGASA declared all its field stations open to the public for special lectures in astronomy. Admission to its Planetarium was free of charge during the Week. Telescope and stargazing sessions were held in several key cities, participated in by hundreds of elementary and high school students and science teachers from various regional centers of the Philippines.

Total solar eclipse of 1995. Astronomy further gained nationwide interest among Filipinos when the total solar eclipse of 1995 was announced by PAGASA in November 1994. A national committee, led by the DOST and PAGASA, was created by the President of the Philippines to promote its observation and documentation. An extensive information campaign and lectures on the eclipse were conducted in many parts of the country, especially in Mindanao where the central path of the eclipse will cross the island province of Tawi-Tawi.

The event was highlighted by the attendance of then Vice President, later President Joseph Estrada, and many top government officials, including the Secretary of the DOST and the Director of PAGASA, to observe the total solar eclipse on 24 October 1995. Two local TV networks set up satellite transmitting equipment at Languyan, Tawi-Tawi, to beam the event nationwide. The TV networks also installed remote transmitting systems in several major cities in northern Luzon, central Visayas and southern Mindanao. Thousands of people, including members of astronomical societies and the radio and press, came to 
the site. Hundreds gathered in the PAGASA stations where a telescope was available for public viewing of the eclipse. A hundred eyepieces made of carton and mylar film were distributed by PAGASA to students and teachers in TawiTawi and to TV crew and cameramen. The Philippine Long Distance Telephone Company set up a temporary satellite telecommunication facility in the area for the use of press reporters.

Discovery of Comet Hyakutake. The discovery of Comet Hyakutake on 30 January 1996, barely two months after the total solar eclipse of 1995, heightened the level of interest in astronomy in the Philippines even more. The public was made aware of the discovery through a press release issued by PAGASA in midFebruary 1996. Increased concern by the public about the possibility of Comet Hyakutake crashing into Earth was perceived through numerous inquiries received by PAGASA as a result of the collision of Comet Shoemaker-Levy with Jupiter from 16 to 22 July 1994.

Celebration of the Centennial of Astronomy in the Philippines in 1997. To sustain the momentum gained during the past two years, PAGASA initiated the issuance of Presidential Proclamation No. 956, declaring 1997 as the Philippine astronomy centennial year and constituting a national committee for its celebration. The PAGASA/DOST was designated as the lead/chair agency with the National Museum of the Department of Education, Culture and Sports (NM/DECS) as vice chair, and the Philippine Information Agency and Manila Observatory as members. Among the activities implemented during the year are the conduct of: (i) information, education and communication (IEC) program in astronomy through press releases and radio/TV interviews; (ii) seminar/workshops for science teachers and students; (iii) symposium during the NAW; (iv) distribution of astronomical posters, grant of honor and recognition awards to five outstanding Filipino astronomers, and carrying out a contest on astronomy, termed as Astro Olympiad; and (v) preparation of a commemorative centennial publication.

The fortuitous discovery and appearance of Comet Hale-Bopp from 20 March to 11 April 1997 lent beneficial support to the celebration of the centennial of astronomy in the Philippines as the interest of the public was maintained at a high level from its discovery up to its disappearance. This momentous event elicited the remark that "even the heavens are celebrating with us" from the chief of the AGSSB.

Astro Olympiad. Astro Olympiad '98 was one of the activities in the DOSTGIA project, entitled "Promotion of Astronomy". The Olympiad was given full support by Dr. William G. Padolina, then secretary of the Department of Science and Technology, who wanted a science-oriented youth and gave encouragement to make the contest an annual activity.

It was a contest in astronomy for high-school and college students in the Metro Manila. The contest consisted of the elimination and final rounds, where 100 and 10 contestants in each level, respectively, were selected. The elimination round was a written examination held at the Philippine Science High School on 27 June 1998. The final round was an oral contest, held at PAGASA on 03 July 1998. A panel of five judges supervised the contest. 
The 10 finalists and the winners for each level were chosen based on the highest scores. Ties in the finals were broken by additional questions for the tying contestants. Prizes were in cash and certificates of recognition for the finalists. Cash prizes (in Philippine pesos) amounted to P25,000 (U.S. \$500) for the first prize, P20,000 (U.S. $\$ 400$ ) for the second, P15,000 (U.S. $\$ 300$ ) for the third and P5,000 (U.S. \$100) each for the seven non-winners in the college level. In the high-school level, the cash prizes were P10,000 (U.S. \$200), P5000 (U.S. $\$ 100$ ), P2500 (U.S. $\$ 50$ ) and P1000 (U.S. \$20), respectively.

In 1999, the contest covered the entire Luzon area, which is composed of seven administrative regions. It applied the same contest rules used in Astro Olympiad ' 98 . The only difference is the increase in prizes of the high-school winners which are P20,000, P10,000, and P5,000 for the first, second and third prizes, respectively.

Grant of Honor and Recognition Award. During the awarding ceremony for the winners of the Astro Olympiad in 1998, plaques of honor and recognition were also distributed to five outstanding Filipinos who have made significant contributions in the field of astronomy. A screening committee led by PAGASA was formed which selected the awardees from those who were Filipino citizens at the time of their application/nomination and whose achievements in astronomy are exemplary. Filipino expatriates who have distinguished themaelves in astronomy were also considered for these awards.

The plaque was named the "Dr. Casimiro del Rosario Award", in honor of the first Filipino Director of the Weather Bureau after the Second World War, who pioneered in astronomy during his tenure. One of the awardees is the retired Director of the then National Geophysical and Astronomical Office, who was chosen because of his important contributions to the IGY Moonwatch Satellite Tracking Program. He also started the the publication of various astronomical data by PAGASA.

The second awardee is a priest who is presently Head of the Upper Atmosphere Division of the Manila Observatory. He is an active member of the American Geophysical Union and has been President of the Philippine Astronomical Society. He has written more than forty papers on astronomy and about the same number on physics and other various topics.

The third recipient of the award is presently the head of the National Museum Planetarium. His most significant accomplishment in astronomy is the promotion of that subject among young people through lectures and telescope and stargazing sessions.

The fourth and fifth awardees are a husband-and-wife team, now based in the United States. This couple's continuous efforts in observing led to the determination of the orbit of asteroid 6282, discovered by Carolyn Shoemaker in 1980, and were also recognized in 1995 by the IAU's Minor Planet Center. The husband is the first Asian to be an Associate Editor of Sky and Telescope.

A special (posthumous) award of recognition was also given to Dr Casimiro del Rosario for his significant contributions and pioneering work in astronomy.

Astronomical Diary. In July 1998, PAGASA announced the issuance, on a monthly basis, of information about some significant astronomical events, in addition to the daily sunrise and sunset data. These publications, called the 
Astronomical Diary, depict the phases and the positions of the Moon, the Sun and the stars and some of the planets and its satellites. The primary aim of the Diary is to enhance the interest and elevate the level of knowledge of Filipinos in science, in general, and in astronomy, in particular.

The Diary received enthusiastic responses from the media and the public, particularly the students. This interest was shown during the occurrence of the Leonids meteor shower in November. The meteor shower drew marked interest due to the predicted Leonids meteor storm.

Seminar/Workshop on Meteorology and Astronomy for Science Teachers. The seminar/workshop is a proposal which was submitted to the Department of Science and Technology for possible funding under its DOST GIA fund. The main objective of the project is to enhance the knowledge and skills in meteorology and astronomy of elementary-school and high-school science teachers to enable them to impart these effectively to their students. The two-week seminar/workshop will cover the entire country, which is composed of 15 regions. To be able to implement the project in these regions, it has a duration of 18 months.

\subsection{Attendance at Various International Meetings and Workshops}

The participation of the Chief of the AGSSB in two workshops, jointly organized by the UN Office for Outer Space Affairs (OOSA) and the International Astronautical Federation (IAF), in Graz, Austria on 15-22 October 1993 and in Jerusalem, Israel on 10-14 October 1994, paved the way for increased interest in space sciences in the Philippines. His attendance at the UN/ESA Workshop on Basic Space Sciences: "From Small Telescopes to Space Missions" in Colombo, Sri Lanka on 11-13 January 1996, enabled the establishment of linkages with international space scientists and astronomers by the Philippines. This is considered as very important for the country as it enabled the Chief of the AsRDS to attend the subsequent workshops organized by the UN OOSA in Bonn, Germany, on 9-13 September, 1996, and by the International Astronimcal Union (IAU) in Kyoto, Japan, on 18-30 August, 1997, and the meeting of the Committee on Peaceful Use of Outer Space (COPUOS) in Vienna, Austria, on 03-14 June ,1996.

During these workshops, she was introduced to several prominent astronomers, who became sympathetic to assist the Philippines in strengthening its astronomical service after she presented a paper on the state of astronomy in the Philippines in the workshop in Bonn.

\subsection{Preparation of Project Proposals}

Donation of a 45-cm telescope by the Japanese Government. A project proposal on the possible donation of a 45-cm astronomical telescope by the Japanese Government to the Philippines was prepared by the Chief, AsRDS, in 1997 as a result of her attendance in a workshop in Bonn in 1996 and the IAU GA in Kyoto in 1997. The proposal is aimed to upgrade the capability of the PAGASA Observatory to observe and to study astronomical objects as well as to enable its AsRDS staff to conduct astronomical researches in the future.

On 19-22 January 1998, Profs. Tomokazu Kogure and Masatoshi Kitamura, respectively, Director of Bisei Astronomical Observatory and Guest Worker of 
the National Astronomical Observatory of Japan, visited, in their personal capacity, the PAGASA Astronomical Observatory, the Department of Physics of the University of the Philippines, and the Manila Observatory. Their missions were not only to assist in the revision of the project proposal but also to assess the current status of research and education in astronomy in the Philippines. They also gave brief lectures in astronomy to some PAGASA astronomers. On 28 March 2000 , the donation was formally approved in a ceremony held at the Department of Foreign Affairs (DFA) in Manila. The DFA Secretary and the Japanese Ambassador signed and exchanged diplomatic notes.

DOST-GIA Project Proposals. (i) Promotion of Astronomy: In May 1998, four $25-\mathrm{cm}$ and one 18- $\mathrm{cm}$ telescopes, one video camera, and one CCD were procured through the DOST Grant-in-Aid (GIA) project "Promotion of Astronomy". The telescopes will be installed in four local regional centers and the CCD at the PAGASA Astronomical Observatory. The main objective of this activity is to promote astronomy in the countryside by allowing the public, particularly the students and the science teachers to observe the occurrences of important astronomical phenomena, thereby increasing their knowledge in this field, if not arousing their interest.

(ii) Upgrading of Time-keeping Equipment: PAGASA, by virtue of Presidential Decree No. 1149 , is mandated by the government as the official timekeeper of the Philippine Standard Time (PST). The Time Service Unit (TSU), a unit under the AsRDS, performs this mandate through the maintenance and dissemination of the PST using its very old timing equipment.

To be able to perform its mandated task to the fullest, this project was prepared with a general objective of providing the national standard for the second of time and frequency to industry, science and technology and other users. The objectives of the proposal will be accomplished through the acquisition of a modern astronomical timekeeping system.

(iii) Three Portable Planetaria from the French Government: Since the two planetaria in the Philippines are located in the island of Luzon, PAGASA realized that the people in the islands of Visayas and Mindanao do not have easy access to the planetaria. To bring astronomy to these places, particularly the remote areas, the AsRDS requested from the French government, through its French Protocol Project in PAGASA, a donation of three (3) portable or mobile planetaria.

Aimed to promote astronomy in the countryside, these planetaria will be brought to these places upon their request on a first-come, first-served basis, at a very minimal fee. The planetariums will be called the "Roving Planetaria". When these materialize, the public can be educated in astronomy with the least time, money and effort.

Application to Different Foreign Training Courses and Fellowships in Astronomy Since there is no university in the Philippines that offers a course in astronomy, some AsRDS personnel will apply for a Monbusho fellowship. They plan to take up a Master of Science degree in Astronomy.

Other AsRDS employees are also eagerly waiting for the International School for Young Astronomers, which is scheduled in Thailand in 2001. The AsRDS hopes that some of its personnel will be able to attend this prestigious training, 
to enable them to gain additional knowledge in astronomy, which may allow them to pursue research activities in this field.

In connection with the arrival of the 45-cm telescope donation from the Japanese Government in September 2000, the Chief, AsRDS undertook a familiarization study on modern telescopes at the Gunma Astronomical Observatory (GAO) of Japan on 06 - 12 March 2000 upon the invitation of Prof. Yoshihide Kozai, GAO Director. Although she has completed this course, she plans to stay at the Observatory for six months or more to undertake a training in astronomy, learn the basic techniques in astronomical observation and conduct an astronomical research. A request for support from the JICA office was made to enable her to realize the plan.

The AsRDS personnel are very optimistic that they can perform astronomical research if they can receive formal training in astronomy. Hence, these fellowships are the key factors that will hasten capacity-building in astronomy in the Philippines.

Application for Associate Membership in the IAU In June 1999, the Philippines through PAGASA submitted its letter of intent to the General Secretary of the IAU to apply for Associate Membership to the Union. The application was made in view of the possible donation of the $45-\mathrm{cm}$ telescope from the Japanese Government. PAGASA believes that the Union can give assistance towards its new mission of revitalizing astronomy in the country and allow the AsRDS personnel to participate actively in regional and global cooperative activities in astronomy. The application was approved during the twenty-fourth General Assembly of the IAU in August, 2000.

\section{Conclusion}

Given the preceding information on the past and present resources and activities in astronomy in the Philippines, it is not difficult to make a projection of the status of the science in the near future. In 1996, it was foreseen that, in the next decade, the development of astronomy in the country will remain as lethargic as it has been for the past four decades, unless drastic positive changes were implemented.

Aware of this possibility, the Chief, AGSSB and the AsRDS staff, headed by its Chief, worked relentlessly since then and spent every effort to promote astronomy throughout the country. Likewise, it was very fortunate that the attendance of the Chief, AsRDS in the UN/ESA workshop in astronomy in Bonn, Germany paved the way towards the wider opening of the door of the international community for the country. She was able to meet some of the important people of the IAU, UN OOSA and the Japanese astronomers who are promoting the Cultural Grant-aid Program of their Government.

The project proposal on the possible donation of a $45-\mathrm{cm}$ telescope from the Government of Japan is considered the best positive drastic action that was made that may lead towards a better prospect for astronomy in the Philippines. The installation of the computer-based telescope will signify a new beginning of astronomy, particularly in the field of research. To celebrate this, the Philippines will bid to host an international workshop on basic space science in the year 
2001, coinciding with the inauguration of the new telescope in the PAGASA Astronomical Observatory.

Ultimately, the successful implementation of some of the revitalizing activities described in this paper and the approval of the application for associate membership of the country to the IAU, will enable the Filipinos to hope for a better and brighter future for astronomy and space science in the Philippines.

\section{Discussion}

Hidayat enquired about the role of the Jesuit Father Hayden. Celebre replied that he had indeed done a lot to promote astronomy in the Philippines and had been one of the lecturers in the 1981 in-house training course of PAGASA. In reply to Orchiston, who asked if interest in the Leonid meteor shower, as well as the solar eclipse and Comet Hyakutake, had been used in revitalizing astronomy, Celebre said that it had. Hingley asked if there were indigenous traditions and legends that could be used to spark interest in astronomy. Celebre replied that there are some, which are taught in primary schools, but she thought it would be difficult to relate them to a modern scientific approach.

Martinez said that, since there is not yet any astronomy at university level in The Philippines, before creating a department of astronomy they might consider introducing some astrophysics $(10 \%$ to $20 \%)$ into physics courses. He pointed out that Wentzel had pioneered this approach with his Astrophysics for Physics Courses and might be able to offer some practical advice. Celebre expressed thanks for the suggestion. 